\title{
Investigation of a rotifer (Brachionus calyciflorus) - green alga (Scenedesmus pectinatus) interaction under non- and nutrient-limi- ted conditions
}

\author{
M. Lürling
}

Aquatic Ecology \& Water Quality Management, Department of Environmental Sciences, Wageningen University, PO Box 8080, NL-6700DD Wageningen, The Netherlands

\begin{abstract}
Two-day life cycle tests with the rotifer Brachionus calyciflorus were run to study the nutritional quality effects to rotifers of Scenedesmus pectinatus grown under non-limiting, nitrogen limiting and phosphorus limiting conditions and the feedback of the rotifers on the food algae. Under nutrient-limited conditions of its algal food Brachionus production was depressed, animals produced fewer eggs and were smaller sized. Clearance rates of Brachionus offered non-nutrient-limited and nutrient-limited food were similar. The number of cells per colony was similar for $S$. pectinatus under nitrogen limited and phosphorus limited conditions both in the absence and presence of Brachionus. Cell volumes of phosphorus limited S. pectinatus were larger than those of nitrogen limited cells. The most dramatic response of the food alga S. pectinatus was observed in non-nutrient-limited conditions: a strong size enlargement occurred only in the presence of Brachionus. This was caused by a higher share of eight-celled colonies and larger individual cell volumes in the presence of rotifers than in their absence. S. pectinatus might gain an advantage of becoming larger in moving out of the feeding window of its enemy, but nutrient limited conditions might undermine the effectiveness of such reaction.
\end{abstract}

Keywords : clearance rate, food quality, grazing, induced defence, morphology, plankton interactions

\section{Introduction}

Predator-prey interactions are crucial processes for the functioning of ecosystems as they represent the flow of energy along the food chains. At the base of typical aquatic food chains the alga-grazer interaction is of major importance because it represents the first step at which material and energy flows up the trophic levels (Lindeman 1942). Understanding the mechanisms that regulate these interactions is a key issue in aquatic ecology, and although quantitative and qualitative effects of algae on zooplankton growth have been studied intensively, the controlling factors are still poorly understood (Brett \& Müller-Navarra 1997). Zooplankton may experience not only energy or food quantity

\footnotetext{
* Corresponding author :

E-mail: miquel.lurling@wur.nl
}

constraints on growth, but also food quality constraints. Energetic limitation depends on algal abundance, while food quality constraints involve algal characteristics such as the biochemical make-up of cells and those that affect ingestion and digestion. The rate at which algal material is ingested and digested by zooplankton depends on algal cell and colony shape and size, wall architecture, absence or presence of spines, bristles or secondary metabolites (Porter 1973, Lampert 1987).

Numerous studies have focused on deciphering what controls zooplankton growth limitation and determines food quality in which zooplankton is represented mostly by Daphnia. Food quality determinants were algal stoichiometry, mainly phosphorus limitation (e.g. Sterner 1993, Urabe et al. 1997, Boersma 2000), biochemical constraints or polyunsaturated fatty-acid limitation (e.g. Müller-Navarra et al. 2000, Park et al. 2002, 
von Elert 2002), and morphology, such as cell wall thickening (Van Donk \& Hessen 1993) and colony formation (Lürling \& Van Donk 1996). In the vast majority of these studies the alga used was Scenedesmus, which is known for its extreme morphological variability (Trainor 1998). In the (chemical or physical) presence of zooplankton, Scenedesmus may increase its size to resist mortality from grazers (Lürling 2003). However, most studies in the wealth of research on effects of algal nutritional quality on the energy flow to zooplankton has been unidirectional, with no feedback between grazers and algae and no focusing on possible algal defences. Studies on divisive colony formation in Scenedesmus also considered one side of the coin as experiments on induced defences in Scenedesmus were run under nutrient replete conditions (Hessen \& Van Donk 1993, Lampert et al. 1994, von Elert \& Franck 1999, Lürling 2003, van Holthoon et al. 2003).

A two-day life cycle test with the rotifer Brachionus calyciflorus, in which multiple broods are produced and the $\mathrm{F}_{1}$ generation also reproduces (Snell \& Moffat 1992), may provide an opportunity to study both sides of the grazer-algae interaction: the nutritional quality aspect on the grazers and their feedback on the algae. Rothhaupt (1995) showed that Brachionus rubens ingested nutrient (N- and P) limited Scenedesmus equally to non-limited cells, but that Brachionus growth was reduced. Also growth of $B$. calyciflorus was reduced when they were fed with nutrient-limited Scenedesmus (Jensen \& Verschoor 2004). Therefore, it is expected that also in the current study nutrient limited food will result in lower rotifer abundance because of nutritional constraints of Brachionus growth. Nutrient limitation in itself probably will not have an effect on the number of cells per colony in Scenedesmus (Sterner \& Smith 1993). However nutrient limited conditions may restrict the ability of Scenedesmus to respond optimally to grazing as active growth appeared to be a precondition for the activation of the morphological defence in Scenedesmus (Lampert et al. 1994). In that respect, it is expected that Scenedesmus will be able to activate its morphological defence only under nutrient replete conditions in the presence of grazers, but not in their absence or under nutrient limited conditions. Hence, the following hypotheses were tested:

1) Nutrient limited Scenedesmus pectinatus will result in lower Brachionus growth.

2) Scenedesmus pectinatus reacts to the presence of Brachionus by enlarged cell size and/or increasing colony size, but this reaction is impaired under nutrient limitation.

\section{Materials and methods}

\section{Organisms}

The green alga Scenedesmus pectinatus v99 was obtained from the culture collection of the University Plovdiv (Bulgaria). The green alga Scenedesmus obliquus SAG 276/3a originates from the culture collection of the University of Göttingen (Germany). Semicontinuous stock cultures of these algae were maintained in $300 \mathrm{ml}$ Erlenmeyer flasks, closed with a cellulose plug, containing $150 \mathrm{ml}$ of modified WC (Woods Hole Chu)-medium (Lürling \& Beekman 1999) with vitamins added (Biotin B1 and B12 at $50 \mathrm{ng} \mathrm{l}^{-1}$, Thiamine HCL at $\left.100 \mathrm{ng}^{-1}\right)$. The flasks were placed in climate controlled room at $20^{\circ} \mathrm{C}$ in continuous light of $60-\mu$ mol quanta $\mathrm{m}^{-2} \mathrm{~s}^{-1}$ provided from above by fluorescent cool-white tubes (Osram L 36W/21-840). For at least a year prior to the experiments, every three weeks aliquots were transferred separately into fresh sterile medium.

The grazer Brachionus calyciflorus Pallas was obtained from Microbiotests Inc. (Nazareth, Belgium) and was supplied as cysts. Cysts were hatched in 100-ml suspensions of the green alga in the above mentioned WC-medium. The hatching flasks were placed on a rotating shaking device at $24^{\circ} \mathrm{C}$ in continuous light of $100-\mu \mathrm{mol}$ quanta $\mathrm{m}^{-2} \mathrm{~s}^{-1}$.

\section{Experimental procedure}

An experiment was conducted to study the effect of $S$. pectinatus nutrient limitation on rotifer growth and vice versa of rotifers on algal growth and morphology. Non-limited $S$. pectinatus from the semi-continuous stock cultures were transferred prior to the experiment into $100 \mathrm{ml}$ Erlenmeyer flasks, containing $50 \mathrm{ml}$ of full WC medium with vitamins added and that were closed with a cellulose plug. These flasks were placed on a rotating shaking table $(60 \mathrm{rpm})$ at $24^{\circ} \mathrm{C}$ in continuous light of $100-\mu \mathrm{mol}$ quanta $\mathrm{m}^{-2} \mathrm{~s}^{-1}$. After three days the algae were transferred again into $100 \mathrm{ml}$ Erlenmeyers that contained either 50-ml full WC-medium (non-limited) or 50-ml nutrient-limited medium. In the N-limited medium the $\mathrm{N}$-concentration was reduced to $50 \mu \mathrm{M} \mathrm{NaNO}_{3}$ (i.e.5\% of the full medium) and in P-limited medium the concentration was reduced to $0.5 \mu \mathrm{M} \mathrm{K}_{2} \mathrm{HPO}_{4}$ (i.e. $1 \%$ of the full medium). To compensate for decreasing potassium concentrations in the reduced $\mathrm{P}$-medium $\mathrm{KCl}$ from a $100-\mu \mathrm{M}$ stock solution was added to obtain the desired $\mathrm{K}$ balance. After three days incubation, algal carbon (C), nitrogen and phosphorus (N- and $\mathrm{P}$ ) -contents were determined as described in Lürling \& Van Donk (1997) and the algae 
were used in a rotifer-growth experiment and a shortterm grazing experiment. This experiment was run in 6 -welled covered tissue plates positioned for two days on a rotating shaking table $(60 \mathrm{rpm})$ at $24^{\circ} \mathrm{C}$ in continuous light of 100- $\mu \mathrm{mol}$ quanta $\mathrm{m}^{-2} \mathrm{~s}^{-1}$. Each well received a $10 \mathrm{ml}$ suspension of non-limited, N-limited or P-limited S. pectinatus all at identical initial concentration of $5 \times 10^{6} \mu \mathrm{m}^{3} \mathrm{ml}^{-1}$. Full WC-medium was used for non-limited algae, medium lacking any $\mathrm{N}$ or $\mathrm{P}$ for treatments with $\mathrm{N}$ - or P-limited $S$. pectinatus, respectively. Three replicate wells for each algal type received 6 freshly hatched (2-3 hours old) rotifers (treatments), while three other replicates received no rotifers (controls). This yielded 3 algal food types (Non-, Nand P-limited S. pectinatus) x 2 treatment (without/with rotifers) $x 3$ replicates $=18$ experimental units.

After two days of incubation the number of rotifers and the number of attached eggs were counted under a dissecting microscope at $25 \mathrm{x}$ magnification. Population growth rates were calculated from the increase in total numbers following $r=\left\{\ln \left(N_{\mathrm{t}}\right)-\ln \left(N_{\mathrm{t}-2}\right)\right\} \mathrm{x} \mathrm{t}^{-1}$ where $r$ is the intrinsic growth rate $\left(\mathrm{d}^{-1}\right), N$ is the number of animals and $t$ is the time (d). Lorica length and width of twenty Brachionus were measured with a Leica Quantimet 500 MC image analyser.

In each well the algal densities and particle size distributions were determined in the size range 2.5 $35 \mu \mathrm{m}$ equivalent spherical diameter using a Coulter ${ }^{\circledR}$ Multisizer II (capillary $100 \mu \mathrm{m}$ orifice width, Coulter Electronics Limited, Luton, England). The numbers of cells per colony were determined microscopically by counting at least 100 aggregates (i.e. unicells and colonies), using a Nikon light microscope at $600 \mathrm{x}$ magnification.

Clearance rates (CR) of B. calyciflorus feeding on non-limited, N-limited or P-limited $S$. pectinatus were determined using a 24-welled culture plate. Each vial contained $1.1 \mathrm{ml}$ of $S$. pectinatus in WC-medium $\left(10^{7} \mu \mathrm{m}^{3} \mathrm{ml}^{-1}, \sim 5 \mathrm{mg} \mathrm{Cl}^{-1}\right) ; 8$ vials were used per algal food type. Four vials of each food type received 20 non-egg bearing female Brachionus, while four others served as animal-free controls. The culture plates were incubated at $25^{\circ} \mathrm{C}$ in the dark for $4 \mathrm{~h}$. Once every hour, settled material was resuspended by gently using a pipette and blow some water with it. After $4 \mathrm{~h}, 1 \mathrm{ml}$ of water was pipetted from each vial and analysed on the numbers of particles and biovolume using the Coulter ${ }^{\circledR}$ Multisizer II. Hereto, each sample 1.0-ml was diluted with 9.0-ml electrolyte solution (ISOTON) and algal size distribution and concentrations were determined in the range from 2.5 to $35 \mu \mathrm{m}$ (ESD; $100 \mu \mathrm{m}$-orifice tube). Rotifer clearance rates $(\mathrm{CR}, \mu \mathrm{l}$ rotifer-1 $\left.\mathrm{h}^{-1}\right)$ were calculated using the following equation (Peters, 1984) :

$$
\begin{gathered}
\mathrm{CR}=(b-a) \times \frac{V}{N} \\
\text { with } b=\left(\frac{\left(\ln \left(A_{C, t=1}\right)-\ln \left(A_{C, j=0}\right)\right)}{\Delta t}\right) \text { and } a=\left(\frac{\left(\ln \left(A_{7, t=1}\right)-\ln \left(A_{T, j=0}\right)\right)}{\Delta t}\right) \text {, where } A_{C, t=\theta}
\end{gathered}
$$

is the initial algal concentration (biovolume in $\mu \mathrm{m}^{3}$ $\mathrm{ml}^{-1}$ ) in controls, $A_{C, t=1}$ is the final algal concentration in controls, $A_{T, t=0}$ is the initial algal concentration in the treatments, $A_{T t=1}$ is the final algal concentration in treatments, $\Delta t$ is the time $(4 \mathrm{~h}), V$ is the culture volume $(1.1 \mathrm{ml})$ and $N$ is the number of animals (20).

\section{Data analysis}

Population growth rates, egg-ratios and clearance rates of B. calyciflorus on non-limited, $\mathrm{N}$-limited or $\mathrm{P}$ limited $S$. pectinatus were analysed running a one-way ANOVA preceded by Levene's equality of variances test and followed by Tukey's HSD post-hoc multiple comparison test. S. pectinatus characteristics like the mean particle volume (MPV) and number of cells per colony were analysed by two-way ANOVA with nutrient conditions and the absence/presence of rotifers as fixed factors. Running $t$-tests tested other differences. All statistical analyses were run in the statistical tool pack SPSS ${ }^{\circledR}$ version 10.1.0.

\section{Results}

\section{Brachionus}

Population growth of Brachionus was the highest on non-limited $S$. pectinatus, intermediate on N-limited and lowest on P-limited S. pectinatus (Fig. 1). A oneway ANOVA indicated that those differences in growth were statistically significant $\left(F_{2,6}=75.9 ; P<0.001\right)$ with Brachionus growth on each food type significantly differing from the others (Tukey's post hoc comparison, $P<0.05)$. The mean number of eggs per rotifer was significantly higher $\left(F_{2,6}=44.1 ; P<0.001\right)$ in animals fed non-limited $S$. pectinatus than those reared on N- or P-limited food (Fig. 1). Brachionus reared on non-limited or N-limited $S$. pectinatus had a significantly longer lorica $\left(F_{2,57}=4.99 ; P=0.010\right)$ than those grown on P-limited food (Fig. 2). The width of nonlimited Brachionus was significantly larger $\left(F_{2,57}=\right.$ $3.5 ; P=0.034)$ than animals fed P-limited $S$. pectinatus (Fig. 2). The short-term grazing experiment showed identical $\left(F_{2,9}=0.52 ; P=0.610\right)$ Brachionus clearance rates $(\mathrm{CR})$ on non-limited and nutrient limited $S$. 

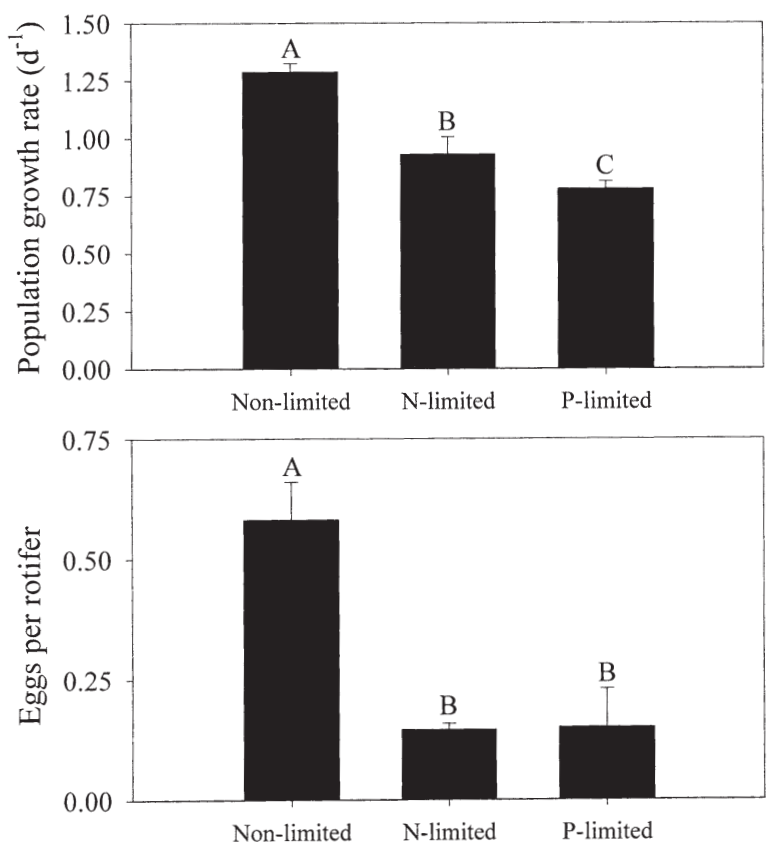

Fig. 1. Population growth rates (upper panel, in $\mathrm{d}^{-1}$ ) and number of eggs per female (lower panel) of Brachionus calyciflorus grown for two days on non-nutrient-limited, nitrogen (N-)-limited and phosphorus (P-)-limited Scenedesmus pectinatus. Error bars indicate one standard deviation $(N=3)$. Different symbols above bars $(\mathrm{A}, \mathrm{B}, \mathrm{C})$ indicate statistically significant differences $(P<0.05)$.

pectinatus (Fig. 3). However, CR estimated from the two-day growth experiment were significantly different $\left(F_{2,6}=5.25 ; P=0.048\right)$. The CR of Brachionus feeding on $\mathrm{N}$-limited food was significantly higher $\left(9.8 \pm 1.9 \mu\right.$ rotifer $\left.^{-1} \mathrm{~h}^{-1}\right)$ than those of animals feeding on either non-limited $\left(5.2 \pm 0.6 \mu\right.$ rotifer $\left.^{-1} \mathrm{~h}^{-1}\right)$ or P-limited food $\left(5.7 \pm 0.8 \mu \mathrm{l}\right.$ rotifer $\left.^{-1} \mathrm{~h}^{-1}\right)$.

\section{Scenedesmus}

The C:P ratio of $S$. pectinatus that was used as food in the rotifer growth experiment as well as the shortterm grazing experiment was the highest in P-limited algae, while the $\mathrm{C}: \mathrm{N}$ ratio was the highest in the $\mathrm{N}$-limited algae (Table I). The mean particle volume (MPV) of N-limited S. pectinatus was significantly smaller than P-limited $S$. pectinatus $\left(F_{2,6}=5.11 ; P=\right.$ $0.05)$ while the numbers of cells per colony were similar (Table I). Moreover, N-limited algal cultures were yellow coloured, whereas non-limited and P-limited cultures were green; N-limited $S$. pectinatus contained significantly less $\left(F_{2,6}=56 ; P<0.01\right)$ chlorophyll- $a$ per unit biovolume than non-and P-limited S. pectinatus did (Table I).

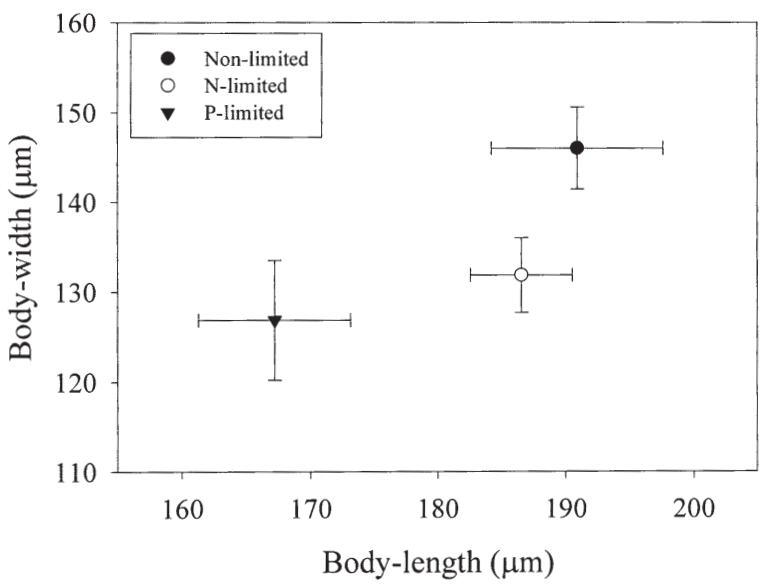

Fig. 2. Body-length and width dimensions $(\mu \mathrm{m})$ of Brachionus calyciflorus grown for two days on non-nutrient-limited, nitrogen (N-)-limited and phosphorus (P-)-limited Scenedesmus pectinatus. Error bars indicate one standard deviation $(N=20)$.

After two days in the rotifer growth experiment, the mean particle volumes (MPV) that had been log transformed prior to statistical analysis to obtain homogeneity of variances were significantly different among $S$. pectinatus populations reared in the absence or presence of Brachionus $\left(F_{1,12}=116.9 ; P<0.001\right)$ and under non- or nutrient-limiting conditions $\left(F_{2,12}=109.8\right.$; $P<0.001)$. The MPVs of N- or P-limited $S$. pectinatus were similar in the absence or presence of Brachionus (Fig. 4). However, in non-limited S. pectinatus the MPV was significantly higher in the presence of rotifers than in their absence (Fig. 4), which is reflected in a significant food types (Non-, N- and P-limited Scenedesmus) $\mathrm{x}$ treatment (without/with rotifers) interac-

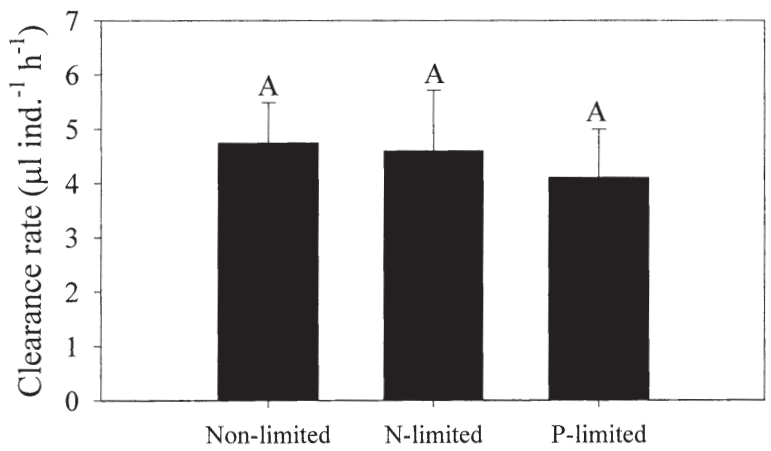

Fig. 3. Clearance rates ( $\mu 1$ rotifer-1 $^{-1} \mathrm{~h}^{-1}$ ) of Brachionus calyciflorus feeding on non-nutrient-limited, nitrogen (N-)-limited and phosphorus (P-)-limited Scenedesmus pectinatus. Error bars indicate one standard deviation $(N=4)$. 
Table 1. Characteristics of Scenedesmus pectinatus from cultures grown under non-limited, nitrogen (N)-limited and phosphorus (P)-limited conditions that were used as food for the rotifer Brachionus calyciflorus. Molar carbon to phosphorus (C:P) and carbon to nitrogen $(\mathrm{C}: \mathrm{N})$ ratios, mean particle volumes $\left(\mathrm{MPV}\right.$ in $\left.\mu \mathrm{m}^{3}\right)$, mean number of cells per colony and amount of chlorophyll-a $\left(\mu \mathrm{g} \mu \mathrm{m}^{-3}\right)$ are given with standard deviations in parentheses $(N=3)$; similar lettering $(\mathrm{A}, \mathrm{B})$ represent homogeneous groups that are not statistically different (Tukey's HSD; $P<0.05$ ).

\begin{tabular}{cccccc}
\hline S. pectinatus & C:P & C:N & MPV & Cells colony $^{-1}$ & Chlorophyll- $a$ \\
\hline Non-limited & $128(29)$ & $3(1)$ & $328.8(16.9)^{\mathrm{AB}}$ & 2.96 & $1.15(0.03) 10^{-8 \mathrm{~A}}$ \\
N-limited & $105(2)$ & $20(8)$ & $296.9(35.0)^{\mathrm{B}}$ & 2.93 & $0.73(0.08) 10^{-8 \mathrm{~B}}$ \\
P-limited & $811(340)$ & $9(5)$ & $375.7(36.0)^{\mathrm{A}}$ & 2.79 & $1.23(0.07) 10^{-8 \mathrm{~A}}$ \\
\hline
\end{tabular}

tion $\left(F_{2,12}=81.6 ; P<0.001\right)$. The two-way ANOVA and post-hoc comparison on the number of cells per colony indicated that they were significantly higher in
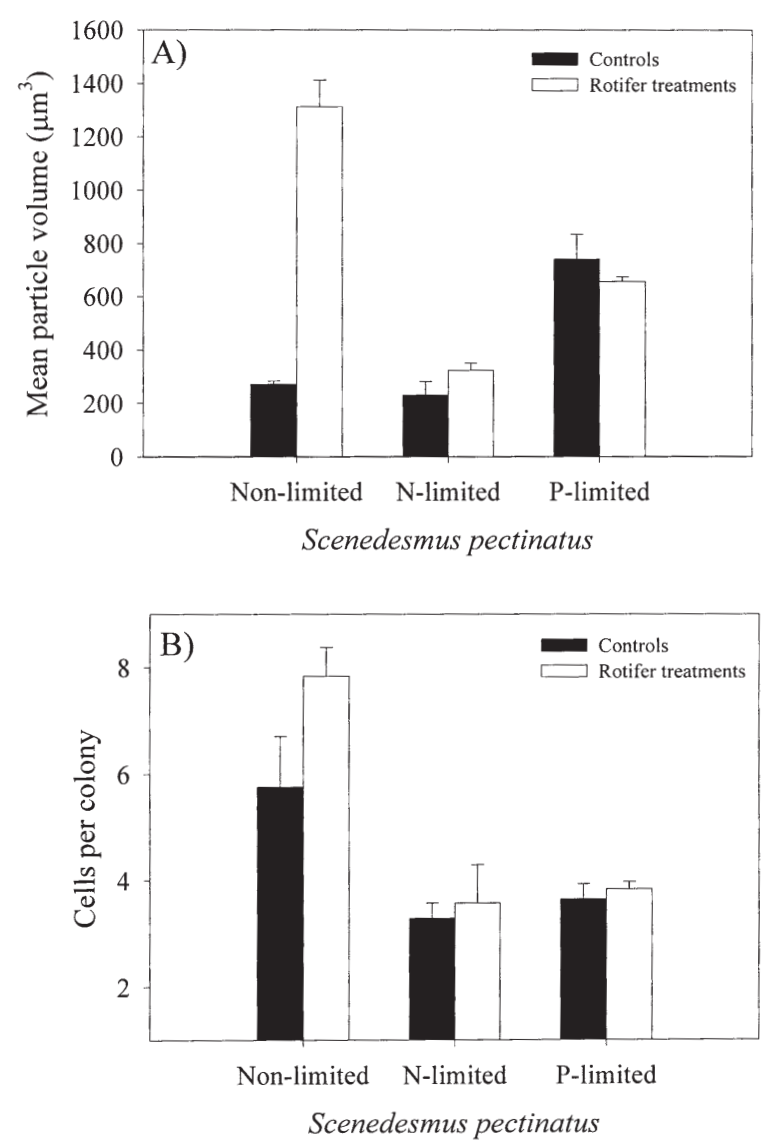

Fig. 4. Mean particle volumes (upper panel $\mathrm{A}$, in $\mu \mathrm{m}^{3}$ ) and number of cells per colony (lower panel B) of Scenedesmus pectinatus grown for two days under non-nutrient-limited, nitrogen (N-)-limited and phosphorus (P-)-limited conditions in the absence (filled bars) and presence (open bars) of the rotifer Brachionus calyciflorus. Error bars indicate one standard deviation $(N=3)$.
S. pectinatus under non-limiting than under nutrient-limiting conditions $\left(F_{2,12}=65.2 ; P<0.001\right)$. Moreover, in the presence of Brachionus the number of cells per colony was significantly higher $\left(F_{1,12}=10.3 ; P=\right.$ $0.007)$ than in their absence, but this was only observed for non-limited $S$. pectinatus (Fig. 4), also indicated by a significant interaction term $\left(F_{2,12}=5.33 ; P=\right.$ 0.022).

Individual cell sizes, expressed as cell volume were significantly influenced by the nutrient conditions $\left(F_{2,12}=64.7 ; P<0.001\right)$ and differed in the absence or presence of rotifers $\left(F_{1,12}=21.4 ; P=0.001\right)$, but only for the non-limited $S$. pectinatus, which caused a significant interaction term $\left(F_{2,12}=31.7 ; P<0.001\right)$. Tukey's HSD post-hoc comparison revealed two homogeneous groups: P-limited cell volumes in absence and presence of rotifers and of non-limited $S$. pectinatus in the presence of rotifers were significantly larger than

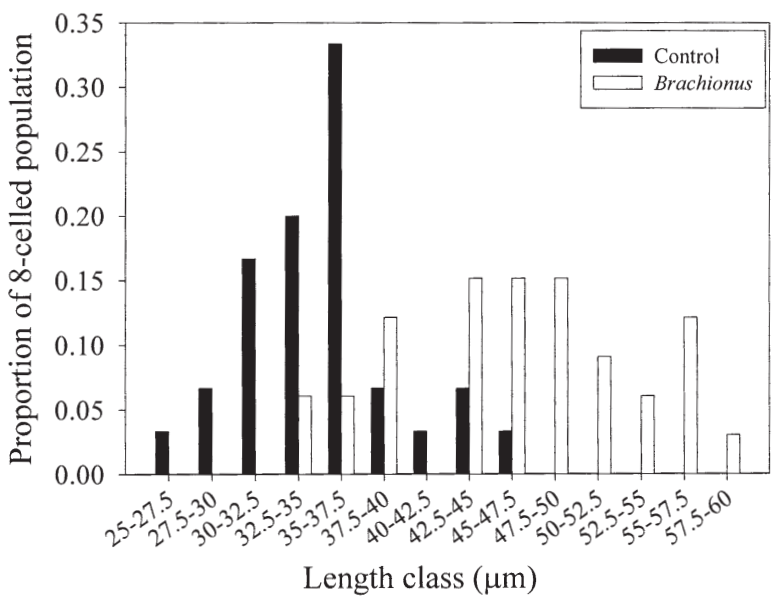

Fig. 5. Frequency distribution of different size classes of eight-celled Scenedesmus pectinatus grown for two days under non-nutrient-limited conditions in the absence (filled bars) and presence (open bars) of the rotifer Brachionus calyciflorus. 
those of N-limited S. pectinatus cells in absence and presence of rotifers and non-limited in the absence of rotifers. Frequency distribution of different size classes of eight-celled $S$. pectinatus under non-limiting conditions, revealed that $45 \%$ of the colonies in the presence of rotifers exceeded the maximum sizes found in the absence of rotifers (Fig. 5). In the absence of rotifers eight-celled colonies of maximally $47.5 \mu \mathrm{m}$ in length were found, while in the presence of rotifers they reached up to $60 \mu \mathrm{m}$ in length (Fig. 5).

Inasmuch as the nutrient composition of the media differed and incubations were placed in continuous light in the two-day experiment, the resulting algal growth rates in the controls were significantly different (one-way ANOVA $F_{2,6}=499.8 ; P<0.001$ ). As expected non-limited medium permitted the highest volumebased growth of $S$. pectinatus $\left(1.49 \pm 0.04 \mathrm{~d}^{-1}\right)$, P-free medium a significantly reduced growth $\left(0.30 \pm 0.08 \mathrm{~d}^{-1}\right)$ and $\mathrm{N}$-free medium supported no growth at all $(-0.01 \pm$ $\left.0.08 \mathrm{~d}^{-1}\right)$. Also particle-based growth was significantly (one-way ANOVA: $F_{2,6}=228.6 ; P<0.001$ and Tukey's HSD; $P<0.05)$ lower in $\mathrm{N}$-free $\left(0.15 \pm 0.16 \mathrm{~d}^{-1}\right)$ and P-free medium $\left(-0.01 \pm 0.03 \mathrm{~d}^{-1}\right)$ than in non-limited medium $\left(1.50 \pm 0.02 \mathrm{~d}^{-1}\right)$. In non-limited medium, particle-based and volume-based growth rates of $S$. pectinatus were similar $(t=0.60 ; P=0.579)$ and also in $\mathrm{N}$-free medium no statistical differences were detected $(t=1.72 ; P=0.161)$. In contrast, for $S$. pectinatus in P-free medium particle-based and volume-based growth were significantly different $(t=6.01 ; P=$ $0.004)$. The positive volume-based growth for these $\mathrm{P}$ limited $S$. pectinatus can be explained by cells becoming larger without dividing: the number of particles at the start and after two days of incubation was similar, i.e. 12500 particles $\mathrm{ml}^{-1}(t=0.10 ; P=0.922)$.

\section{Discussion}

\section{Brachionus}

The quality of S. pectinatus as food for Brachionus was influenced by the nature of the nutrient-limitation: the highest growth rate was found on non-limited $S$. pectinatus, N-limited food permitted intermediate growth and the lowest Brachionus growth occurred when P-limited S. pectinatus was the food source. These results are in concordance with the hypothesis that nutrient-limited algal food reduces growth of Brachionus and are comparable to those found by Rothhaupt (1995) and Jensen \& Verschoor (2004) who offered $S$. obliquus that differed in nutritional status to Brachionus rubens and B. calyciflorus, respectively.
The nutritional constraints were not only reflected in lowered population growth rates, but also in the mean size of $B$. calyciflorus that was significantly reduced under nutrient limitation, especially when feeding on P-limited cells. Similar observations have been made for Daphnia feeding on non-, N- or P-limited Scenedesmus where animals reached the largest body-size on non-limited food (Lürling \& Van Donk 1997, Urabe \& Sterner 2001). Moreover, the reduced length and width dimensions of B. calyciflorus under nutrient limitation find support in the lower body volume at first reproduction and first day somatic growth found by Jensen \& Verschoor (2004).

Brachionus also produced a significantly smaller number of eggs on nutrient limited food than on nonlimited food, which has been observed in Daphnia too (Urabe \& Sterner 2001). Nutrient limited food results in a limited amount of resources to be allocated to the three basic functions: maintenance, growth and reproduction and allocation to one of these functions implies less availability to the others. Feeding on N- or Plimited algae did not hamper the rotifers to produce offspring but probably at the price of reduced somatic growth and a lower reproductive rate. The latter is corroborated by the study of Jensen \& Verschoor (2004) in which lower lifetime fertility was found in B. calyciflorus that was reared on nutrient limited S. obliquus.

As a consequence of the experimental design with different medium composition in the non-limited and nutrient-limited treatments, growth (and morphology) of the $S$. pectinatus was affected in the two-day experiment. In relation to the rotifers especially the volumebased growth is of interest, because positive values for growth reflect an increase in the actual biomass. Growth was the highest in the non-limited algae in non-limited medium and thus differences in food quantity could have influenced the population growth. However, food concentrations in all treatments were high and in the range that is expected to permit maximal growth (Rothhaupt 1990b, 1995). The lowest food concentration was found in the treatments with N-limited $S$. pectinatus (geometric mean of $1.5 \mathrm{mg} \mathrm{C}^{-1}$ ), which caused in the study of Rothhaupt (1995) a growth reduction of $25 \%$ compared to animals fed non-limited food at the same concentration. The $28 \%$ reduction found in the current study is in close match with the result of Rothhaupt (1995). Although food quantity may limit Brachionus production, the concentrations in the current study were such that the different population growth of Brachionus is most probably caused by the distinct food qualities of non-limited and 
nutrient limited Scenedesmus. Inasmuch as the reduced population growth, egg production and size of $B$. calyciflorus under $\mathrm{N}$ - and $\mathrm{P}$-limitation is also found for other food types and zooplankton these responses appear to be a more general pattern in herbivorous zooplankton.

The short-term feeding experiment showed no differences in $B$. calyciflorus clearance rates. This result is in good agreement with that of $B$. rubens, which ingested nutrient (N- and $\mathrm{P}$ ) limited $S$. obliquus equally to non-limited cells (Rothhaupt 1995). These findings do not support the digestion resistance hypothesis, which postulates that under nutrient-limitation chlorophytes like Scenedesmus gain increased resistance against digestion through a thickening of the wall (Van Donk \& Hessen 1993, 1995, Van Donk et al. 1997). The duration of the short-term experiment was such that it exceeded several times the maximum gut passage times of B. calyciflorus (Starkweather \& Gilbert 1977) and it can therefore be expected that if viable gut passage would have occurred, it would have been expressed in lower clearance rates. Although Scenedesmus has been found to pass through the gut of cladocerans (Van Donk \& Hessen 1993) and rotifers (Pourriot 1977), Brachionus is able to crush algae with a mastax that is specialised for grinding food items, which might explain the absence of differences in clearance rates in the short-term grazing experiment. In the two-day growth experiment, however, rotifer clearance rates differed. The highest clearance rates were found for $B$. calyciflorus feeding on N-limited food and significantly lower clearance rates for animals feeding on P-limited and non-limited $S$. pectinatus. The difference in clearance rates for Brachionus feeding on N-limited and P-limited $S$. pectinatus can be explained from the differences in food concentrations (Rothhaupt 1990a). The clearance rates that were estimated of Brachionus feeding on non-limited $S$. pectinatus were similar to those that preyed on P-limited food. Because clearance rates drop continuously with food concentration above a critical concentration (Rothhaupt 1990a), the similar clearance rates in this case could be the result of the larger animals in non-limited conditions that through higher feeding activity might have outbalanced expected lower clearance rates. On the other hand, it remains possible that in both non-limited and P-limited conditions lower clearance rates were obtained, but that these were not detected in the experimental set-up employed in the current study. In the short-term grazing experiment the algae were all in the same size range (see Table I), however after the two days growth experiment distinct differences occurred (see Fig. 4). P-li- mited S. pectinatus had gained in size, N-limited dropped in size and the most dramatic increase was observed in the non-limited $S$. pectinatus, but only in the presence of rotifers. The large eight-celled S. pectinatus colonies probably reached sizes beyond the ingestion capacity of B. calyciflorus (Rothhaupt 1990a). Further research should incorporate estimates of feeding efficiencies of Brachionus supplied with identical amounts of such distinct morphologies of the food.

\section{Scenedesmus}

Under non-limiting conditions $S$. pectinatus became much larger through an increase in the number of cells per colony as well as larger individual cell size. The increased number of cells per colony can be explained from selective feeding on colonies with fewer than eight cells and from induction of the eight-celled morph (Lürling 2003). Eight-celled S. pectinatus colonies were also observed in the absence of rotifers, but more than $45 \%$ of the eight-celled colonies in the presence of rotifers exceeded the maximum size (length and width) found in populations without natural enemies. A larger cell size and consequently larger colonies appears to be linked to the presence of grazers and not the result of selective feeding. This reaction most probably will have moved the majority of the population that were eight-celled colonies with dimensions of $46 \mathrm{x}$ $37 \mu \mathrm{m}$ out of the feeding window of $B$. calyciflorus. These rotifers feed most efficiently on particles with an equivalent spherical diameter around $10 \mu \mathrm{m}$ (Rothhaupt 1990a). The feeding efficiency curve of B. calyciflorus is approximately bell shaped and lower ingestion rates are reflected in lower Brachionus growth rates (Rothhaupt 1990b). The underlying mechanism is most probably interference due to the handling time needed for processing large algae. Hence, the result is in favour of the hypothesis that an increment of cell/colony dimensions in the presence of natural enemies could be an efficient response to minimise the risk of being consumed (Lehman 1988). In fact, enlargement of prey to reduce or prevent attack success of natural enemies is a widespread phenomenon among aquatic taxa in the animal kingdom ranging from multicellular organisms such as fish (Brönmark \& Miner 1992), cladocerans (Dodson 1989), and rotifers (Halbach 1971), to unicellular ciliates (Kusch 1993). However, although divisive colony formation is a wellknown example of an induced defence in phytoplankton and has been found across different algal taxa in both the freshwater and marine environment (e.g. Hessen \& Van Donk 1993, Tang 2003), the concomitant enlargement of cells has gone unnoticed. 
In contrast to the strong size enlargement of $S$. pectinatus in reaction to the presence of $B$. calyciflorus under non-nutrient-limited conditions, no reaction of $S$. pectinatus to the rotifers was observed in $\mathrm{N}$ - or P-limited cultures. Thus, nutrient-limitation could undermine the effectiveness of a defence against grazers through lowering the algal growth rate and concomitantly the ability to form protective colonies or at least by reducing the speed in which the defence can be activated. This is corroborated by the observation that also for colony formation in another Scenedesmus species active growth appeared to be a precondition for the activation of a morphological defence (Lampert et al. 1994). However, especially under P-limitation when growth rates drop other morphological properties like cell wall structure and covering might determine largely the resistance of algae to grazing (Van Donk \& Hessen 1993). To fully understand the impact of such morphological changes in the alga-grazer interaction assessing the population consequences of both grazers and algae in prolonged exposure studies is needed. It is conceivable that through nutrient recycling (Moegenburg \& Vanni 1991, Urabe 1993) some growth of nutrient-limited $S$. pectinatus might take place, which could make the formation of colonies possible in more than the 48 hours that were used in the current experimental set-up. The formation of colonies and enlargement of cells will require time to be activated and fully expressed, because the algae need time to accumulate a certain amount of protoplasm, which is formed during photosynthesis, before the cells undergo division (Setlík et al. 1972, Siver \& Feeda 1982). Hence, population consequences to algal prey and rotifers may be more pronounced in longer exposures.

When P-limited S. pectinatus were placed for two days in P-free medium, still a positive volume-based growth rate was found, but the number of cells per $\mathrm{ml}$ were similar. This means that P-limited cells were no longer capable of division and probably accumulated photosynthesis products in their cells. In contrast, N-limited cells did not increase in size, but rather decreased in size and some cell division still occurred. An increase in cell size in P-limited chlorophytes has been observed in several other studies but for $\mathrm{N}$-limited cells patterns are less clear and both increased and decreased cell sizes have been found (Van Donk \& Hessen 1993, 1995, Kilham et al. 1997, Lürling \& Van Donk 1997).

The results of the current study showed that under nutrient-limited conditions Brachionus production is strongly depressed, animals produced fewer eggs and were smaller sized. The food alga $S$. pectinatus sho- wed a strong size enlargement in the presence of $\mathrm{Bra}$ chionus, but only under non-limited conditions. Hence, to activate this response growth appears to be essential and nutrient limited conditions seem to undermine it. S. pectinatus might gain an advantage of becoming larger in moving out of the feeding window of its enemy, but nutrient limited conditions might undermine the effectiveness of such reaction.

\section{Acknowledgements}

Drs Detlina Belkinova and Ruben Mladenov (Univeristy of Plovdiv, Bulgaria) are cordially thanked for the delivery of Scenedesmus pectinatus. This study was supported by a fellowship of the Royal Netherlands Academy of Arts and Sciences (KNAW).

\section{References}

Boersma M. 2000. - The nutritional quality of P-limited algae for Daphnia. Limnol. Oceanogr., 45, 1157-1161.

Brett M.T. \& Müller-Navarra D.C. 1997. - The role of highly unsaturated fatty acids in aquatic food web processes. Freshwater Biol., 38, 483-499.

Brönmark C. \& Miner J.G. 1992. - Predator-induced phenotypical change in body morphology in crucian carp. Science, 258, 13481350 .

Dodson S.I. 1989. - The ecological role of chemical stimuli for zooplankton : predator-induced morphology in Daphnia. Oecologia, 78, 361-367.

Halbach U. 1971. - Zum Adaptivwert der zyklomorphen Dornenbildung von Brachionus calyciflorus Pallas (Rotatoria). Oecologia, 6, 267-288.

Hessen D.O. \& Van Donk E. 1993. - Morphological changes in Scenedesmus induced by substances released from Daphnia. Arch. Hydrobiol., 127, 129-140.

Jensen T.C. \& Verschoor A.M. 2004. - Effects of food quality on life history of the rotifer Brachionus calyciflorus Pallas. Freshwater Biol., 49, 1138-1151.

Kilham S.S., Kreeger D.A., Goulden C.E. \& Lynn S.G. 1997. - Effects of nutrient limitation on biochemical constituents of Ankistrodesmus falcatus. Freshwater Biol., 38, 591-596.

Kusch J. 1993. - Induction of defensive morphological changes in ciliates. Oecologia, 94, 571-575.

Lampert W. 1987. - Feeding and nutrition in Daphnia. Pages 143192 in Peters, R.H. \& De Bernardi, R. (eds) Daphnia. Memorie dell'Istituto Italiano di Idrobiologia, 45.

Lampert W., Rothhaupt K.O. \& von Elert E. 1994. - Chemical induction of colony formation in a green alga (Scenedesmus acutus) by grazers (Daphnia). Limnol. Oceanogr., 39, 1543-1550.

Lehman J.T. 1988. - Selective herbivory and its role in the evolution of phytoplankton growth strategies. Pages 369-387in Sandgren, C.D. (ed) Growth and reproductive strategies of freshwater phytoplankton. Cambridge Univ. Press.

Lindeman R.L. 1942. - The trophic-dynamic aspect of ecology. Ecology, 23, 399-418.

Lürling M. 2003. - Phenotypic plasticity in the green algae Desmodesmus and Scenedesmus with special reference to the induction of defensive morphology. Ann. Limnol. -Int. J. Limnol., 39, 85101.

Lürling M. \& Beekman W. 1999. - Grazer-induced defenses in Scenedesmus (Chlorococcales; Chlorophyceae); coenobium and spine formation. Phycologia, 38, 368-376. 
Lürling M. \& Van Donk E. 1996. - Zooplankton-induced unicell-colony transformation in Scenedesmus acutus and its effect on growth of herbivore Daphnia. Oecologia, 108, 432-437.

Lürling M. \& Van Donk E. 1997. - Life history consequences for Daphnia pulex feeding on nutrient limited phytoplankton. Freshwater Biol., 38, 693-709.

Moegenburg S.M. \& Vanni M.J. 1991. - Nutrient regeneration by zooplankton: effects of nutrient limitation of phytoplankton in a eutrophic lake. J. Plankton Res., 13, 573-588.

Müller-Navarra D.C., Brett M.T., Liston A.M. \& Goldman C.R. 2000. - A highly unsaturated fatty acid predicts carbon transfer between primary producers and consumers. Nature, 403, 74-77.

Park S., Brett M.T., Müller-Navarra D.C. \& Goldman C.R. 2002. Essential fatty acid content and the phosphorus to carbon ratio in cultured algae as indicators of food quality for Daphnia. Freshwater Biol., 47, 1377-1390.

Peters R.H. 1984. - Methods for the study of feeding, grazing and assimilation by zooplankton. Pages 336-412 Downing, J.A. \& Rigler, F.H. (eds) A manual on methods for the assessment of secondary production in fresh waters. IBP Handbook $17,2^{\text {nd }}$ edition, Blackwell, Oxford.

Porter K.G. 1973. - Selective grazing and differential digestion of algae by zooplankton. Nature, 244, 179-180.

Pourriot R. 1977. - Food and feeding habits of rotifera. Arch. Hydrobiol. Beih. Ergebn. Limnol., 8, 243-260.

Rothhaupt K.O. 1990a. - Changes of the functional responses of the rotifers Brachionus rubens and Brachionus calyciflorus with particle sizes. Limnol. Oceanogr., 35, 24-32.

Rothhaupt K.O. 1990b. - Population growth rates of two closely related rotifer species: effects of food quantity, particle size and nutritional quality. Freshwater Biol., 23, 561-570.

Rothhaupt K.O. 1995. - Algal nutrient limitation affects rotifer growth rate but not ingestion rate. Limnol. Oceanogr., 40, 12011208.

Šetlík I., Berková E., Doucha J., Kubín Š., Vendlová J., \& Zachleder V. 1972. - The coupling of synthetic and reproduction processes in Scenedesmus quadricauda. Algol. Stud., 7, 172-213.

Siver P.A. \& Freeda S.J. 1982. - The interaction of growth rate and cell cycle on the number of cells in a Scenedesmus coenobium. Proc. Penn. Acad. Sci., 56, 133-137.

Snell T.W. \& Moffat B.D. 1992. - A 2-d life cycle test with the rotifer Brachionus calyciflorus. Environ. Toxicol. Chem., 11, 1249-
1257.

Starkweather P.L. \& Gilbert J.J. 1977. - Radiotracer determination of feeding in Brachionus calyciflorus: the importance of gut passage times. Arch. Hydrobiol. Beih. Ergebn. Limnol., 8, 261-263.

Sterner R.W. 1993. - Daphnia growth on varying quality of Scenedesmus: mineral limitation of zooplankton. Ecology, 74, 23512360.

Sterner R.W. \& Smith R.F. 1993. - Clearance, ingestion and release of N and P by Daphnia obtusa feeding on Scenedesmus acutus of varying quality. Bull. Mar. Sci., 53, 228-239.

Tang K.W. 2003. - Grazing and colony size development in Phaeocystis globosa (Prymnesiopheceae): the role of a chemical signal. J. Plankton Res., 25, 831-842.

Trainor F.R. 1998. - Biological aspects of Scenedesmus (Chlorophyceae)-phenotypic plasticity. Nova Hedwigia, Beiheft, 117, 1-367.

Urabe J. 1993. - Coupling N to P cycling through grazers' activities: food quality and nutrient release by zooplankton. Ecology, 74, 2337-2350.

Urabe J., Clasen J. \& Sterner R.W. 1997. - Phosphorus limitation of Daphnia growth: is it real? Limnol. Oceanogr., 42, 1436-1443.

Urabe J. \& Sterner R.W. 2001. - Contrasting effects of different types of resource depletion on life history traits in Daphnia. Funct. Ecol., 15, 165-174.

Van Donk E. \& Hessen D.O. 1993. - Grazing resistance in nutrientstressed phytoplankton. Oecologia, 93, 508-511.

Van Donk E. \& Hessen D.O. 1995. - Reduced digestibility of UV-B stressed and nutrient-limited algae by Daphnia magna. Hydrobiologia, 307, 147-151.

Van Donk E., Lürling M., Hessen D.O. \& Lokhorst B. 1997. - Changed cell wall morphology in nutrient deficient phytoplankton and the significance for grazers. Limnol. Oceanogr., 42, 357-364.

van Holthoon F.L., van Beek T.A., Lürling M., Van Donk E. \& de Groot $Æ$. 2003. - Colony formation in Scenedesmus: a literature overview and further steps towards the chemical characterisation of the Daphnia kairomone. Hydrobiologia, 491, 241-254.

von Elert E. \& Franck A. 1999. - Colony formation in Scenedesmus: grazer-mediated release and chemical feature of the infochemical. J. Plankton Res., 21, 789-804.

von Elert E. 2002. - Determination of limiting polyunsaturated fatty acids in Daphnia galeata using a new method to enrich food algae with single fatty acids. Limnol. Oceanogr., 47, 1764-1773. 